\title{
The Effect of Cash Transfers on Fertility: Evidence from Argentina
}

\author{
Santiago Garganta ${ }^{1}$ (D) Leonardo Gasparini ${ }^{1}$ • \\ Mariana Marchionni ${ }^{1} \cdot$ Mariano Tappatá $^{2}$
}

Received: 17 December 2015/Accepted: 12 October 2016/Published online: 28 October 2016

(C) Springer Science+Business Media Dordrecht 2016

\begin{abstract}
In 2009 Argentina introduced a large poverty-alleviation program (AUH) that provides monthly cash transfers per child to households without workers in the formal sector. In this paper we study the potential unintended effect of this program on fertility. We apply a difference-in-difference strategy comparing the probability of having a new child among eligible and ineligible mothers both before and after the program inception. The intention to treat estimations suggest a significant positive impact on fertility in households with at least one child (around 2 percentage points), but no significant effect on childless households. Given the short time window since the implementation of the AUH, we are unable to identify whether this positive effect reflects changes in the timing of births or in the equilibrium number of children.
\end{abstract}

Keywords Fertility $\cdot$ Cash transfers $\cdot$ Social protection $\cdot$ AUH $\cdot$ Argentina

\begin{abstract}
This research project was carried out in part while Mariana Marchionni and Leonardo Gasparini were visiting scholars at the University of British Columbia. The paper includes material from Santiago Garganta's Ph.D. dissertation at Universidad Nacional de La Plata. We are grateful to seminar participants at the Annual Conference of the Canadian Economic Association (Vancouver), Asociación Argentina de Economía Política (Posadas), Network of Inequality and Poverty (Buenos Aires), Universidad de San Andrés and Universidad Nacional de La Plata, and to Kevin Milligan, Alessandro Cigno, Ana Navarro, Jorge Paz, Roxana Maurizio, María Laura Alzúa, Alberto Porto, and Walter Cont, for their valuable comments and suggestions. We are also grateful to three anonymous referees for their insightful suggestions that contributed to improve a previous version of the paper. All errors and omissions are our sole responsibility.
\end{abstract}

Santiago Garganta

sangarganta@hotmail.com

1 CEDLAS, Facultad de Ciencias Económicas, Universidad Nacional de La Plata and CONICET,

La Plata, Argentina

2 McDonough School of Business, Georgetown University, Washington, DC, USA 
JEL Classification H55 $\cdot$ I38 $\cdot$ J13

\section{Introduction}

Since the late 1990s most countries in Latin America have extended their social protection systems through the implementation of cash transfer programs targeted to poor households. The evidence suggests that these programs have played an important role in the short-term reduction of poverty and income inequality in the region, and have also implied long-term positive impacts through the promotion of assets and human capital accumulation in poor families (Fiszbein et al. 2009). However, cash transfer programs are usually designed with features that could also generate some unintended effects. In this paper we focus on the impact of these programs on fertility. More specifically, we investigate whether a povertyalleviation program recently implemented in Argentina (Asignación Universal por Hijo, AUH), which provides a monthly cash transfer per child, encourages couples to have a child to become eligible, or induces current participants to increase the size of their families to, in turn, increase the amount of the transfer. These effects could arise given the eligibility criteria of the program; in particular, (i) transfers are on a per-child basis instead of a lump-sum household benefit, and (ii) the program roster remains open to new participants.

Although the existence and quantitative importance of the effect of povertyalleviation programs on fertility is relevant for the current social protection debate in Latin America, the empirical literature on this issue is still incipient. The discussion on whether financial support affects fertility has been particularly focused on developed countries. For the United States, there is a large literature that examines the impact on fertility of tax provisions and social policies benefiting families with children. In general, these studies find mild or no significant effects, but the evidence is relatively mixed and not fully conclusive. For instance, Whittington et al. (1990) show that the personal exemption for dependents from the federal income tax affected the decision to have a child and raised the aggregate fertility rate. However, Acs (1996) finds no significant impact on childbearing from welfare policies that deliver payments to young mothers. Regarding the interpretation of the U.S. evidence in this area, Hoynes (1997) concludes that the existing empirical results are not convincing of an actual effect on fertility, whereas in contrast, Moffitt (1998) argues that the evidence suggests that the welfare system actually generates a significant impact on fertility. ${ }^{1}$ More recent studies from other developed countries find a positive and significant causal link between financial incentives and fertility, particularly arising from certain policies that aim to increase birth rates. Milligan (2005) finds a strong increase in fertility from a pronatalist transfer program in the Canadian province of Quebec. Similarly, Cohen et al. (2013) conclude that Israel's child subsidy generates a positive, statistically and

\footnotetext{
${ }^{1}$ For a more extensive review of this empirical literature in the United States see Blau and Robbins (1989), Fairlie and London (1997), Grogger et al. (2002), Dyer and Fairlee (2003), Rosenzweig (1999), Joyce et al. (2003) and Kearny (2004).
} 
economically significant price effect on overall fertility. In addition, Laroque and Salanié (2013) find that tax incentives affect fertility decisions in France.

In this paper we study Asignación Universal por Hijo (Universal Child Allowance or AUH), a conditional cash transfer (CCT) program launched in November 2009 aimed at reducing poverty in Argentina. The AUH provides monthly cash transfers per child to households whose members are unemployed or working in the informal sector (i.e. unregistered). This is a massive anti-poverty program that delivers cash payments to more than 3.5 children (1.8 million households) each month and amounts to around $0.8 \%$ of Argentina's GDP. The implementation of the AUH garnered ample political support as it proved successful at alleviating the high poverty and income inequality levels in the country (Gasparini and Cruces 2010).

Like most cash transfer programs in Latin America, the AUH was created with no explicit demographic goal. ${ }^{2}$ However, it establishes a direct relationship between the amount of the benefit and the number of children in the household. Given the popularity and large scale of the AUH program, it is important to inform policymakers of the impact on fertility decisions by the at-risk population. Unfortunately, it is not simple to identify the causal effect of the AUH on fertility. First, the program was not randomly assigned in the population. Second, there is no data that might allow one to track individual beneficiaries of the AUH over time. We therefore use Argentina's national household survey (Encuesta Permanente de Hogares, EPH) to identify the AUH eligible households and compare their fertility outcomes with the rest of the population over time. This strategy of differences-indifferences is effective in alleviating several endogeneity problems that arise when comparing heterogeneous observations.

We find that the AUH increased fertility by about 2 percentage points $(30 \%$ increase) among the program's potential beneficiaries. The effects are not homogeneous across households, however. In particular, we find a significant fertility increase only for those couples who already had a child. Nevertheless, we are unable to identify whether this positive effect reflects changes in the timing of births or in the equilibrium number of children.

Our paper contributes to the literature that analyzes the indirect effects of CCT programs on fertility. ${ }^{3}$ The existing empirical evidence is scarce but it is growing, particularly in Latin America and in other developing countries where similar policies have been implemented. For instance, Nandi and Laxminarayan (2016) estimate that a large CCT program in India (Janani Suraksha Yojana, JSY), which delivers a financial incentive to disadvantaged women conditional on institutional childbirths, generated a

\footnotetext{
${ }^{2}$ Some countries have introduced programs to explicitly affect fertility rates. In some developed countries the literature of financial incentives on fertility decisions has focused mainly on the evaluation of policies specifically designed to counteract the fall in birthrates (see Milligan 2005; Cohen et al. 2013). Also, some developing countries have used financial incentives to intentionally discourage fertility. See for instance Oster (2005) and Ebenstein (2010) for a detailed explanation of China's policy in this regard.

3 This objective places our study within a more extensive literature of CCTs that also analyzes the effects on other variables associated with long-run poverty. For instance, on the impact of CCT programs on labor market outcomes see Alzúa et al. (2013), Gonzalez-Rozada and Pinto (2011) and Azuara and Marinescu (2013).
} 
significant rise in the probability of childbirth or pregnancy. In contrast to this finding, Palermo et al. (2015) report that the Zambian child grant program has no significant impact on the overall fertility rate of that country. The specific evidence in Latin America shows no clear consensus, although as of yet there are few studies that evaluate the impact of CCTs on this particular outcome. Signorini and Queiroz (2011) find a positive albeit not significant impact on fertility of Bolsa Família, the main CCT program in Brazil. In Uruguay, Amarante et al. (2016) find a positive effect of the $P A N E S$ program on fertility, but when they restrict the analysis around the eligibility threshold, the fertility estimates are small and not statistically significant. ${ }^{4}$ Finally, Stecklov et al. (2007) find mixed evidence in the region: while the Social Protection Network program in Honduras increased fertility by between 2 and 4 percentage points, the programs PROGRESA in Mexico and Family Assistance Program in Nicaragua had no impact on childbearing. ${ }^{5}$ Unlike the AUH, the latter two programs provide lump-sum and not per-child transfers. We relate this critical difference in program design to the different findings.

The rest of the paper is organized as follows. In "The Program and Fertility Incentives" section we describe the AUH program and discuss the implicit incentives on fertility. "Data and Methodology" section describes the data used in this study and lays out the estimation strategy. "Results" section presents the main findings and the last section concludes.

\section{The Program and Fertility Incentives}

Asignación Universal por Hijo (AUH) is a national program launched in Argentina in November 2009 (decree 1602/09) that provides monthly cash transfers per child with the condition that parents must be unemployed or informal (unregistered) workers with income below the minimum wage. ${ }^{6}$ The benefit consists of monthly transfers per child under 18 years old, and it is paid up to a maximum of 5 dependent children. ${ }^{7}$ The money is transferred to one of the parents of the child, typically the mother. By November 2009, the monthly transfer for one child was set at AR\$ 180 , equivalent to around US\$ 50 or $13 \%$ of the Argentinean minimum wage. For a typical informal poor household with three children the benefit implied an increase of around 50\% in total household income. These values place the AUH benefit among the largest in Latin America (Stampini and Tornarolli 2013). The monthly amount per child has been adjusted annually to shield the purchasing power of the subsidy against inflation. As Fig. 1 shows, the nominal monthly transfers

\footnotetext{
${ }^{4}$ However, the main goal of this study is to evaluate the impact of the PANES program on birth outcomes, particularly on birthweight.

5 Todd et al. (2012) find that the Red de Protección Social in Nicaragua generates an increase in birth spacing.

${ }^{6}$ Registered workers already had a similar benefit. A public system of child allowances for formal workers was first introduced in Argentina in 1957, partly as the result of advocacy by the Catholic Church and labor unions. The current system was implemented by law 24.714 in 1996. See Groisman et al. (2014), Moreno (2006), and Rofman and Olivieri (2011).

7 The program also provides transfers to households with disabled children with no age restrictions, and to pregnant women.
} 
have increased by more than $20 \%$ each year, though its purchasing power has remained fairly constant over time. ${ }^{8}$

Prior to 2009 there were some CCTs in Argentina (Programa Jefes de Hogar, Familias por la Inclusión Social, and Seguro de Capacitación y Empleo), which were phased out after the implementation of the much larger AUH program. The number of beneficiaries of poverty-alleviation programs jumped at the end of 2009 after the inception of AUH from around 1.2 million to more than 3.5 million, while the mean value of transfer per child almost doubled. Given this situation, we interpret the results of our paper as mainly the effect of a large expansion in the social protection system in Argentina generated by the introduction of this CCT program. ${ }^{9}$

The AUH is a poverty-alleviation program whose main objective is to increase the well-being of low-income households. Transfers are made to parents not registered in the national social security system, with children up to 18 years old, who comply with some conditions on school attendance and health controls. These conditions are easily audited by the government. ${ }^{10}$ The decree creating the program considers only those earning less than the minimum wage eligible. However, since this condition is almost impossible to monitor for the group of informal workers, this limitation is inconsequential in practice, which means that in principle middle and high-income informal workers may participate in the AUH program. In practice, however, many of those belonging to this (small) group may opt out of the program for reasons related to social responsibility, stigma or others. Information from the national expenditure survey for 2012 (ENGHo) reveals that there are AUH beneficiaries not complying with the explicit income bound established by the decree. Nevertheless, the distribution of children actually receiving the AUH is strongly concentrated on the poorest income deciles: only $10 \%$ of the participants belong to the $50 \%$ richest households. ${ }^{11}$

The program covers a large proportion of the Argentinean population, the majority belonging to low-income strata. In 2010, the AUH made payments for

\footnotetext{
${ }^{8}$ Given the discrepancies regarding the accuracy of official CPI statistics, we use private CPI estimations from Estudio GB for the Greater Buenos Aires area.

9 Unfortunately, we cannot explore whether the impact started with the announcement of the program or with the effective delivery of the cash transfers, because the program was announced and implemented in just two months. The program was announced on October 29th, 2009 and the decree that created the new program (1602/09) was signed by the president that day. The first transfers were made in November and by December the program had reached 3,408,222 beneficiaries, almost its equilibrium size. For instance, one year later, in December 2010, the number of beneficiaries was 3,513,064 (ANSES 2012). In addition, the announcement of a large conditional cash transfer program in October 2009 was hardly expected, since just four months before, in June 2009, the government had announced that social policy was going to be based on workfare programs aimed at specific geographic areas and at-risk groups, and not on broad-based cash transfer programs (Groisman et al. 2014; Rofman and Olivieri 2011; Garganta and Gasparini 2015).

${ }^{10} 20 \%$ of the monthly benefit can only be made effective if the following requirements are met: vaccination and health checks for children under 4 years old and attendance at a public school for those between 5 and 18 years old. In addition, the transfer is contingent on the beneficiary not receiving any allowances from existing contributory and tax-relief programs.

11 The ENGHo is the only source of information in Argentina that enables one to capture both eligible households and effective beneficiaries of the AUH. The ENGHo only provides information for the year 2012, and hence it is not useful for the purpose of our study.
} 


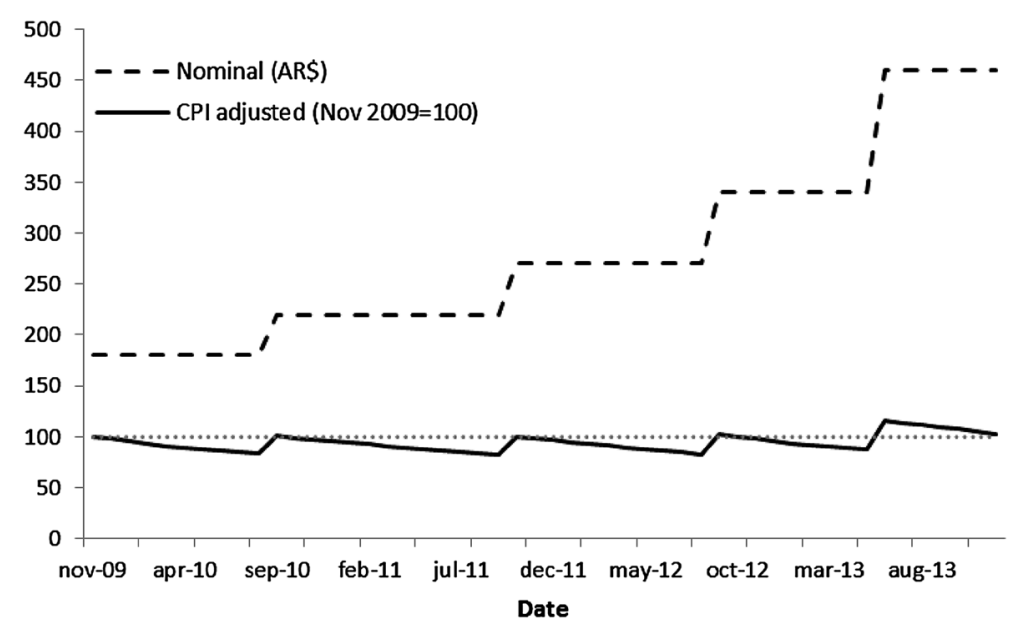

Fig. 1 AUH monthly transfer per child. Source: Author's estimations based on official information from the AUH program and CPIs from Estudio GB

more than 3.5 million children, which represent $29 \%$ of all children under 18 years old in the country. The annual budget of the program, around $0.8 \%$ of GDP, is one of the highest in Latin America. The large scale of the AUH suggests a potentially big impact on poverty, income inequality, and also on labor and demographic variables.

Regarding the effects on the labor market, Garganta and Gasparini (2015) find that the AUH had a significant disincentive to the formalization of beneficiaries, although they do not find evidence of an incentive to informality for registered workers. Concerning other outcomes, the existing estimates, which typically ignore potential changes in individuals' behavior after the program, suggest that the AUH had a significant impact on the reduction of poverty and income inequality, and some positive results on school attendance levels (Gasparini and Cruces 2010; Agis et al. 2010; Paz and Golovanevsky 2014; D'Elia and Navarro 2011; Rofman and Oliveri 2011; Edo and Marchionni 2015). As for the effects of the program on demographic variables, Pacharoni and Ronconi (2014) present descriptive evidence suggesting a break in the global fertility rate around one year after the implementation of the AUH, but to the best of our knowledge there are no studies assessing the causal impact of the program on fertility decisions. ${ }^{12}$

\section{Incentives on Fertility}

There is a long-lasting debate about the impact of policy-alleviation programs on childbearing, a debate that dates back to the arguments of Malthus against the English Poor Laws in the early 19th century. The theoretical literature has

${ }^{12}$ Cigno and Pinal (2004) study fertility decisions in a poor province in Argentina in the framework of the endogenous survival probability hypothesis, although for a period prior to the implementation of the AUH. 
highlighted several channels by which those programs may affect fertility decisions differently, and the empirical literature has been far from conclusive, finding heterogeneous results across settings. More recently, there has been interest in the analysis of the fertility impact of CCTs, i.e. programs that make cash payments to poor households conditional on their behavior, basically sending their children to school and complying with basic health check-ups.

A typical fertility decision-making model suggests that a CCT may affect the demand for children, through both an income and a substitution effect, and the supply of children. ${ }^{13}$ A CCT has an income effect as it implies more resources in the household; the sign of that effect is, however, theoretically ambiguous. In fact, the income effect may contribute to a fall in fertility if, as income grows, parents tend to reduce the number of children in favor of investing in their quality (Becker 1960, Schultz 1997). Although this is conceivable, "the shift from high quantity/low quality to low quantity/high quality generally occurs over generations and it is unclear whether such changes occur over the relatively short periods during which these programs have operated," as Stecklov et al. (2007) have noted.

A CCT has also a substitution effect as it affects the relative price of the quantity and quality of children. The way a program affects these prices is highly dependent on the setting. There are four key elements to consider: (i) whether the roster is closed at the start of the program or remains open; (ii) whether the transfers are on a per household or a per child-basis, (iii) the amount of the transfer, and (iv) the costs associated with complying with the conditionalities. If a CCT has an open roster, delivers generous benefits on a per child-basis and the costs of complying with the education and health conditions are low, then the relative price of a new child is significantly lowered, and we would expect an increase in the incentives for childbearing. Consistent with these arguments, Stecklov et al. (2007), based on experimental data, find a significant fertility incentive in the Family Assistance Program in Honduras, a program with an open roster that delivers benefits on a per child-basis. However, they did not find significant results in the Mexico's PROGRESA-Oportunidades and Nicaragua's Social Protection Network, two programs with closed rosters and benefits on a per household-basis.

Besides the discussed effects on the demand for children, a CCT may also affect the supply of children; for instance, by including the provision of contraceptives and family planning information that could lower fertility among beneficiary families.

Based on the previous discussion, we believe that the AUH program in Argentina may have a positive effect on fertility given the eligibility criteria and its particular design, which reduces the direct cost of quantity of children (independent of quality). First, the AUH household roster remained open after the initiation of the program, i.e. new households could become eligible by having a child. Second, the AUH provides per child transfers that are not decreasing with the number of children; therefore, families with less than 5 children under 18 years old could increase the amount of benefits by having an additional child. Third, the benefits are relatively large compared to household income, at least larger than in most other

\footnotetext{
${ }^{13}$ See for instance the model in Stecklov et al. (2007) based on Becker (1960), Beker and Lewis (1973) and Rosenzweig and Schultz (1985).
} 
similar programs in Latin America. Fourth, the cost of meeting the conditions is relatively low for beneficiaries, given that public health and public education have wide coverage and are completely free of charge in Argentina, and considering the fact that most poor households were already behaving the way the program requires: vaccination rates and enrollment rates in primary schools were both above $99 \%$ before the program was implemented. ${ }^{14}$ Finally, no supply-side elements aimed at reducing fertility were included in the program. The fact that the AUH was not created as a temporary subsidy and received wide support from all political parties in the country, reinforces the view that the AUH will be a permanent policy and hence the incentives on childbearing.

Nevertheless, even if the AUH creates incentives for childbearing, it could still be a minor factor in the decision to procreate, which depends on a large number of non-economic factors. ${ }^{15}$ The effect could be negligible if the sensitivity of fertility behavior with respect to monetary incentives is low, or the magnitude of the new incentive is relatively small. Only the empirical evidence can reveal the significance and quantitative relevance of the effect of the AUH on fertility.

\section{Heterogeneity in Impact}

The potential effects of the program are likely heterogeneous. In particular, the decision whether to have a first child or not could be less elastic to monetary incentives than the decision to have an additional child. In fact, evidence from the demographic literature suggests that there are differences in the determinants of childbearing intentions in the transition to parenthood and of higher-order births (Philipov et al. 2006; Billari et al. 2009). The analysis has focused on sociopsychological factors as a way to explain childbearing intentions and has made use of the Theory of Planned Behavior (Ajzen 1991), which considers intentions to be dependent on attitudes towards childbearing (i.e. perceived costs and benefits), subjective norms (i.e. perceived normative pressure), and behavioral control (i.e. perceived ability to have and raise a child). Billari et al. (2009) provide evidence that the impact of these factors is parity-specific. In particular, they find that attitudes, which depend on economic incentives, are more important in the intensive margin (higher parities) than in the extensive margin (first births).

In two recent papers, Aaronson et al. (2014) and Baudin et al. (2015) propose models of fertility that distinguish between the extensive and the intensive margins. Although these papers are focused on different issues than the ones treated here (fertility transitions and historical trends in childlessness rates in the U.S.), they both highlight the fact that the extensive margin of fertility may behave differently from the intensive margin, and that economic incentives do not always lead the two margins to respond in the same direction, due to different non-convexities.

\footnotetext{
14 The conditions of the AUH may be more relevant only for the last years of high school, when dropouts increase. However, it is unlikely that fertility decisions now are highly affected by the potential cost of sending a youngster to (a free of charge) high school in about 16 years.

15 Of course, there are cases where fertility is not a decision (e.g. impossibility to get pregnant, or forced pregnancy), and the role of economic incentives are null.
} 
Another issue to note is that the implementation of the program may affect the overall number of children that a couple decides to have and/or the timing or spacing of births. The cash transfer could, for instance, encourage parents to advance their childbearing in order to take advantage of the program, without altering the total number of children desired. Unfortunately, given the limitations of our data (a short time frame) we will not be able to differentiate between the 'quantum' and 'tempo' effects.

\section{Data and Methodology}

We use microdata from Argentina's national household survey (Encuesta Permanente de Hogares, EPH) conducted by the National Statistical Office (INDEC). The EPH covers 31 large urban areas, which represent $62 \%$ of the total country population. The EPH collects information on demographic, education, labor and income variables at the household and individual level. Unfortunately, it does not include questions to identify AUH beneficiaries. Consequently, we define the treatment and control groups based on AUH eligibility, and therefore perform an intention-to-treat (ITT) analysis.

Our sample consists of households with women between 16 and 45 years of age. The treatment group includes all low-income households where none of the adult members is a formal (registered) worker. In the treatment group, we include households that belong to the bottom four deciles of the household per-capita income distribution and test our results to other specifications. ${ }^{16}$ Households in the treatment group could have children and hence meet all the requirements to receive the AUH transfer, or have no children but could become eligible if they decided to have a child. ${ }^{17}$

The control group combines three different subgroups: (i) non-poor, informal households; (ii) poor, formal households; and (iii) non-poor, formal households. Since formality is easily monitored by the government, the possibility that individuals included in control groups (ii) and (iii) receive AUH transfers is very unlikely. Regarding group (i), as explained above, whether non-poor informal workers opt out of the program is bound to social responsibility and stigma effects. We return to this point later in this section.

We measure fertility using information on the presence of newborns one year after we initially observe the household in the survey. The EPH uses a rotation scheme that allows us to track the same household during a period of one and one quarter year. Specifically, if a household is sampled for the first time in quarter $t$, it

\footnotetext{
16 Our data comes from the national household survey (EPH) and not from an evaluation survey of the program. It is thus very unlikely that people misreport any variable in our data source in order to affect the probability of becoming eligible to the AUH program. Although there are concerns that self-reported income in the survey is under-reported, the ranking in the distribution is probably not affected very much by this phenomenon (Deaton 2003; Gasparini et al. 2013), as a result, households in the first four deciles of the self-reported income distribution are likely those in the bottom deciles of the actual income distribution.

17 We also carry out a separate analysis for these two groups.
} 
Table 1 Percentage of households with newborns: Households with a woman aged 16-45

\begin{tabular}{llll}
\hline & $\begin{array}{l}\text { Treatment } \\
\text { (i) }\end{array}$ & $\begin{array}{l}\text { Control } \\
\text { (ii) }\end{array}$ & (i)-(ii) \\
\hline Before AUH & 6.16 & 5.28 & 0.88 \\
After AUH & 7.83 & 5.29 & 2.54 \\
Difference After-Before & 1.67 & 0.01 & 1.66 \\
\hline
\end{tabular}

Source: Author's calculation based on EPH microdata (2004-2012)

Note Binary newborn variable equals 1 if one year after the household is initially observed, there is a new child younger than 1 year old in the household. Before AUH = quarter 12004 to quarter 32009 . After $\mathrm{AUH}=$ quarter 42009 to quarter 32012

would also be surveyed in quarters $t+1, t+4$ and $t+5$. We generate a binary newborn variable that takes the value 1 if in the household there is any child younger than 1 year old in $t+5$ but not in $t$ or $t+1 .{ }^{18}$ All the other household characteristics are from the first quarter that the household was surveyed.

We use information on households surveyed (for the first time) from 2004 quarter 1 to 2012 quarter 3. For each quarter we have around 3000 households. Since the AUH was launched in November 2009, the pre-intervention period includes all quarters previous to 2009 quarter 4 . Table 1 displays the proportion of households with newborns in the treatment and control groups, before and after the program implementation.

Naturally, the treatment and control groups are heterogeneous in many observable and unobservable characteristics. We show in Table 2 that households differ significantly in many dimensions. In general, households in the treatment group have more members, are younger, less educated, and, by construction, earn lower incomes than the control group. Given these differences and in order to estimate the program impact on fertility decisions, we use a difference-in-difference methodology (DD), which focuses on the comparison of the differences in the outcome of interest between the treatment and control group, before and after the policy implementation (Card 1990; Card and Krueger 1994). This methodology is convenient for its potential effectiveness to avoid several endogeneity problems that arise when comparing outcomes for heterogeneous individuals (Bertrand et al. 2004).

The identification assumption in this paper is that, in the absence of the AUH program, the fertility trends for both treatment and control groups would have been similar. In the next section we carry out common trends and placebo tests to increase the credibility of this crucial identification assumption. Also, we assume that there is no other event contemporaneous with the AUH that could have

\footnotetext{
18 Our newborn variable allows for some waiting time for pregnancy. Since the EPH does not provide information on age in months for children under 1 year old, even if we assume that the fertility decision is taken in time $t$, we cannot know the exact duration of the delay. Also, even for a given delay there can be some inclusion error, i.e. children conceived before time $t$ who were born in $t+2$ or $t+3$, when we do not observe the household. Unfortunately, the EPH has no information on pregnancy either. If this data existed, it would be possible to extend the window and also to more accurately distinguish whether births in early 2010 correspond to fertility decisions that were taken after or before the AUH inception.
} 


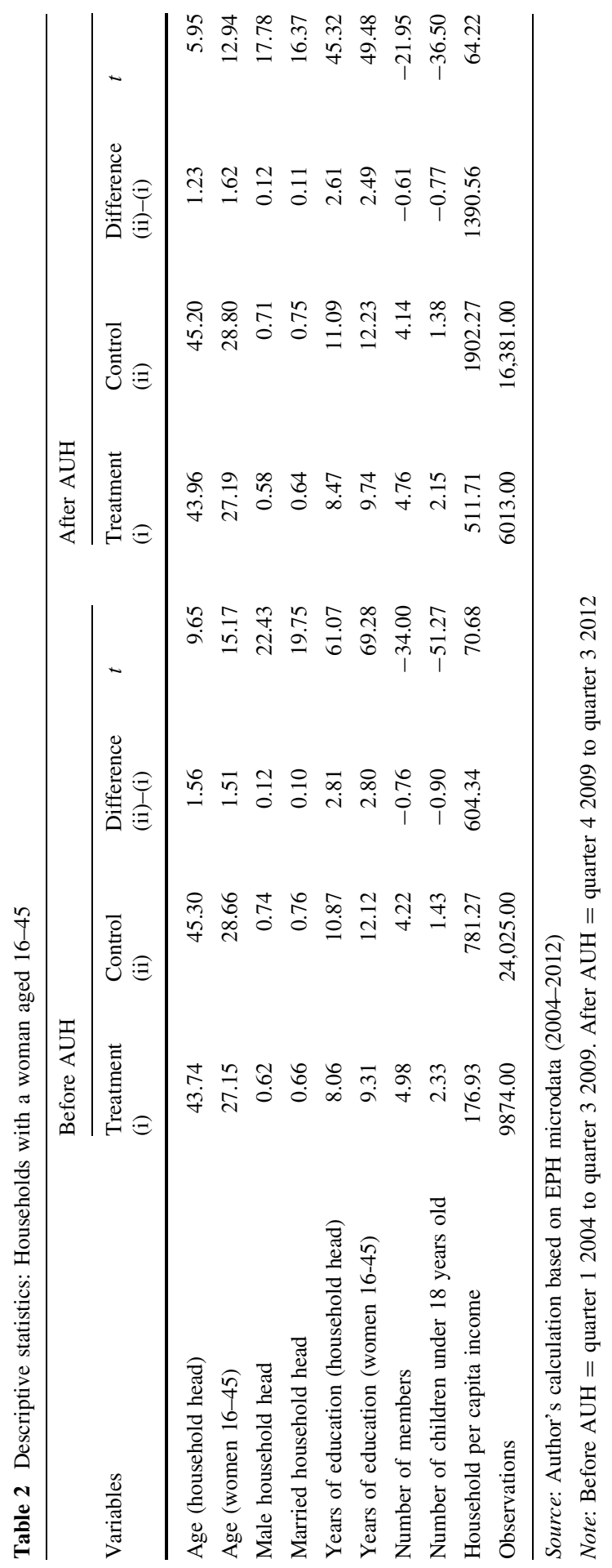


generated a differential impact between groups on fertility outcomes. This assumption does not seem strong: the literature stresses that the AUH was nearly the only -and by far the main- social policy innovation in Argentina during the period of analysis (Bertranou 2010; D'Elia and Navarro 2011; D'Elia et al. 2010; Groisman et al. 2014; Lustig et al. 2012; and Rofman and Oliveri 2011).

The following equation provides a standard linear specification of the DD model:

$$
F_{i t}=\propto+\beta_{1} T_{i t}+\beta_{2} \text { After }+\gamma\left(T_{i t} \cdot \text { After }\right)+\theta X_{i t}+u_{i t}
$$

$F_{i t}$ is the relevant outcome, a binary variable indicating the presence of a newborn in household $i$ one year after time $t$. Variable $T$ is an indicator variable for the treatment group, After indicates periods after the AUH implementation and $X$ includes a set of individual and household-level controls. ${ }^{19}$

The model in Eq. (1) assumes that unobserved events do not have a differential impact on fertility outcome across groups. In other words, considering only two time periods $(t=1 ; 0)$, the mean difference between treatment $(T)$ and control $(C)$ groups is given by

$$
D D=\left(F_{1}^{T}-F_{0}^{T}\right)-\left(F_{1}^{C}-F_{0}^{C}\right)
$$

According to this DD linear specification, it is easy to show that

$$
D D=\gamma+\left(u_{1}^{T}-u_{0}^{T}\right)-\left(u_{1}^{C}-u_{0}^{C}\right)
$$

If the expected value of the last two terms is zero, then DD provides a consistent estimator of the treatment effect. Given that the program assignment is not random, that condition becomes the fundamental assumption of this methodology, which allows causal interpretation of the $\gamma$ parameter.

The same analysis can be carried out under a nonlinear specification. In that case, the conditional expectation of the dependent (binary) variable is a nonlinear function. Analytically,

$$
P\left(F_{i t}\right)=\Phi\left(\propto+\beta_{1} T_{i t}+\beta_{2} \text { After }+\gamma\left(T_{i t} \cdot \text { After }\right)+\theta X_{i t}\right)
$$

where $P($.) denotes probability. The impact of the program is estimated as

$$
D D=\Phi\left(\alpha+\beta_{1}+\beta_{2}+\gamma+\theta X_{i t}\right)-\Phi\left(\alpha+\beta_{1}+\beta_{2}+\theta X_{i t}\right)
$$

The treatment effect is the incremental probability effect of the coefficient of the interaction term (Puhani 2012). Being $\Phi($.) a strictly monotonic nonlinear function, the sign of $\gamma$ always coincides with the sign of the treatment effect. These results apply to all nonlinear models with this parametric structure. In particular, in this paper we use a Probit model to estimate the causal effect of the treatment (the AUH program) on the probability of having a newborn.

As noted above, we apply an ITT strategy, i.e. our treatment group is comprised of eligible households, and thus may include households that do not actually participate in the program. It is likely that the proportion of eligible households not

$\overline{19}$ We also include region and time fixed effects in the estimations. 
participating in the program is small, since admission and participation costs are low, the AUH is a very well-known program extensively promoted by the government, media, and other institutions, and it can be easily requested without any intermediary. Unfortunately, there is no official information about the program's take up rate. Based on administrative records of the number of beneficiaries (ANSES 2012) and the eligible population identified from the EPH, we estimate that around $80 \%$ of eligible children were receiving the transfer six months after the program's inception. When nobody in the control group receives the program, the ratio of the intention-to-treat estimate and the program take-up rate gives us the effect of the program on the actual beneficiaries. Moreover, if take up is random, the estimated effect is also representative of the impact of the program on the average household (Duflo et al. 2006).

The only way we have to evaluate whether or not the take up is random is by using microdata from the national household expenditure survey (Encuesta Nacional de Gastos de los Hogares, ENGHo). Unlike the EPH, the ENGHo allows for the identification of the actual beneficiaries of the program, along with the eligible population. The shortcoming of the ENGHo is that it is conducted every ten years. The last available data corresponds to the survey carried out in 2012, which explains why we resort to the EPH in our paper. Based on the ENGHo, we estimate that $84 \%$ of eligible children in the first four deciles of the per capita income distribution (our treatment group) are beneficiaries of the $\mathrm{AUH}$, and we find no evidence that take up is associated with observable characteristics such as family income, education and age of the head of household. ${ }^{20}$ Moreover, there are virtually no beneficiaries in formal households since the registration system of formal workers implies the automatic exclusion from the program.

\section{Results}

As shown in Table 1, the proportion of households with newborns in the treatment group (poor and informal) increased approximately 1.7 percentage points after the AUH implementation, whereas the corresponding mean value for the control group remained almost unchanged. For the treatment group, the increase is sizeable: it represents $27 \%$ of the pre-intervention value. In the rest of this section we review the identification assumption and examine whether this result holds in a multivariate regression framework, adding controls, restricting the sample, and searching for heterogeneous effects.

Table 3 shows the results of a Probit model of the probability of having a newborn, restricting the sample to households with at least one woman between 16 and 45 years old (Sample 1). In that model, the coefficient of the interaction variable between the treatment dummy ( $T$ equals 1 if poor and informal household) and the After dummy (equals 1 if household is observed after 2009 quarter 4) is positive and statistically significant for all specifications. Models 1, 2, and 3 in the

\footnotetext{
${ }^{20}$ These variables are never statistically significant to explain the probability of being a beneficiary of the AUH using alternative specifications of a linear probability model.
} 
Table 3 Effect of the AUH on the probability of a newborn: Difference in difference estimates

\begin{tabular}{llll}
\hline & $(1)$ & $(2)$ & $(3)$ \\
\hline$T^{*}$ after & $0.0157^{* *}$ & $0.0156^{* *}$ & $0.0143^{* *}$ \\
$T$ & $(0.00764)$ & $(0.00724)$ & $(0.00661)$ \\
& -0.00142 & $-7.61 \mathrm{e}-06$ & -0.000208 \\
After & $(0.00413)$ & $(0.00404)$ & $(0.00367)$ \\
& 0.00123 & 0.000482 & -0.00770 \\
Women's and/or household head's characteristics & Yes & $(0.00313)$ & $(0.0113)$ \\
Other demographic characteristics & No & Yes & Yes \\
Regional and time dummies & No & No & Yes \\
Observations & 56.293 & 56.293 & Yes \\
Pseudo $R^{2}$ & 0.029 & 0.058 & 56.293 \\
\hline Source: Author's & $(0.0336)$ & 0.062 \\
\hline
\end{tabular}

Source: Author's estimations based on EPH microdata (2004-2012)

Note 1 The sample includes all households with at least one woman between ages 16 and 45

Note 2 Probit estimations. Marginal effects reported. Dependent binary variable: newborn, equals 1 if one year after the household is initially observed, there is a new child younger than 1 year old. $T$ equals 1 for informal and poor households (bottom four deciles of the household per capita income distribution)-; After equals 1 in the period quarter 4 2009-quarter 3 2012. Women's and/or household heads characteristics $=$ gender, age, squared age, educational level and marital status. Other household characteristics $=$ number of members and number of children under 18 years old. Region fixed effects (6 regions) and time fixed effects (quarters). Clustered robust standard errors in parenthesis $* p<0.10$; ** $p<0.05$

table progressively control for women's and/or household heads' characteristics (gender, age, age squared, educational level and marital status), other household characteristics (number of members, number of children under 18 years old), region fixed effects (6 regions), and time fixed effects (quarters). ${ }^{21}$ The treatment effect, which is almost unchanged across specifications, represents a mean increase of around $30 \%$ in the probability of having a newborn, as compared to what would have happened in the absence of the program.

In the EPH survey, family relationships among household members are only recorded in terms of the household head (e.g. spouse, child, father or mother of that member). Thus, we consider alternative nested samples to progressively improve the identification of the multiple mother-child relationships within each household. In Table 4 we estimate the treatment effect for alternative samples: (i) the original sample containing all households with at least one woman between 16 and 45 years of age (Sample 1), (ii) households with women between 16 and 45 years of age who are either a household head, spouse, daughter, or daughter-in-law of the household head (Sample 2), and (iii) households with women in the same age bracket who are the household head or the spouse (Sample 3). The treatment effect is positive and statistically significant for all cases. Sample 3 provides the best option for the

\footnotetext{
${ }^{21}$ We carried out several robustness checks by changing the definition of the treatment group (in particular changing the definition of "poor" to more or less than four deciles). All the results hold. Results are available upon request.
} 
Table 4 Effect of the AUH on the probability of a newborn: Difference in difference estimates. Alternative samples

\begin{tabular}{llll}
\hline & Sample 1 & Sample 2 & Sample 3 \\
\hline$T^{*}$ after & $0.0143^{* *}$ & $0.0194^{* *}$ & $0.0204^{* *}$ \\
$T$ & $(0.00661)$ & $(0.00849)$ & $(0.00870)$ \\
& -0.000208 & 0.00103 & 0.00324 \\
After & $(0.00367)$ & $(0.00540)$ & $(0.00445)$ \\
& -0.00770 & $0.0202^{*}$ & -0.00210 \\
Women's and/or household head's characteristics & $(0.0113)$ & $(0.0115)$ & $(0.00894)$ \\
Other demographic characteristics & Yes & Yes & Yes \\
Regional and time dummies & Yes & Yes & Yes \\
Observations & Yes & Yes & Yes \\
Pseudo $R^{2}$ & 56,293 & 43,768 & 35,868 \\
\hline
\end{tabular}

Source: Author's estimations based on EPH microdata (2004-2012)

Note Probit estimations. Marginal effects reported. Sample 1: all households with a woman aged 16-45; Sample 2: households with women aged 16-45 who are either household head, spouse, daughter or daughter-in-law of the household head; Sample 3: households with a woman aged 16-45 who is the household head or the spouse. Clustered robust standard errors in parenthesis $* p<0.10$; ** $p<0.05$. See notes to Table 3 for more specifications about the regressions

identification of the mother-child relationship, but it implies a considerable reduction in the number of observations. For this reason, Sample 2 will be used for the remaining analysis: it provides greater precision than Sample 1, and avoids losing too much information, as would occur with Sample 3.

\section{Assessment of the Identification Strategy: Placebo Experiments and Parallel Trends Test}

A crucial assumption of any diff-in-diff strategy is that, in the absence of the program, the outcome in the treatment group would have moved in tandem with the outcome in the comparison group. This underlying assumption cannot be proved, but confidence in its validity could be enhanced through a series of checks and tests. To that aim we first consider the observed unconditional trends of the outcome of interest (i.e. the probability of a newborn) for both the treatment and the control group. Figure 2 shows a similar trend between eligible and ineligible households for the period prior to AUH implementation. The fertility pattern clearly changed after the introduction of the program: while the outcome in the control group remained relatively constant, there was a significant upward shift in the percentage of newborns among the eligible group.

This finding is confirmed through a parallel trends test. Specifically, we run a model of the outcome of interest on a constant, the treatment dummy, quarter dummies, and the interactions between these two latter groups of variables. We then 


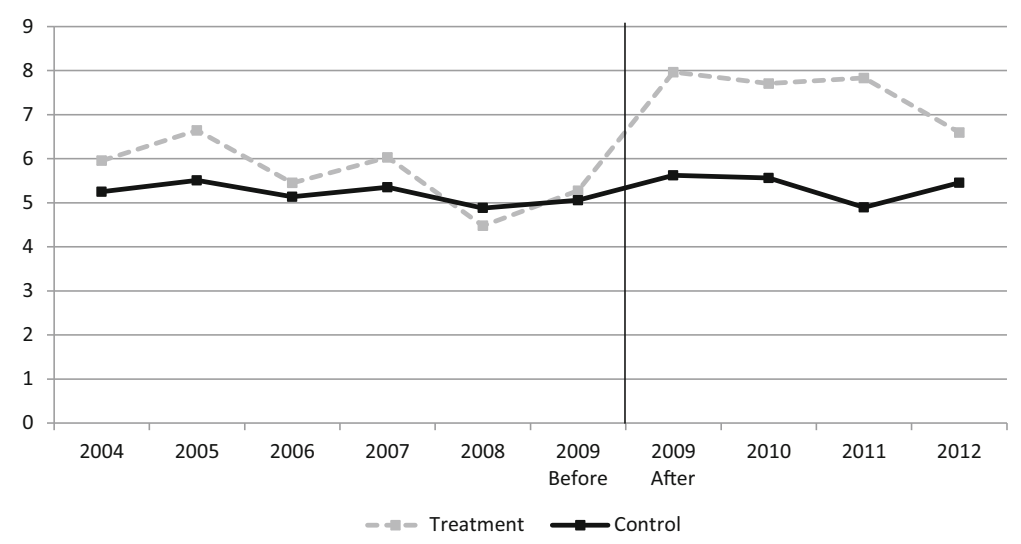

Fig. 2 Percentage of households with newborns. Treatment and control groups. Source: Author's estimations based on EPH microdata (2004-2012). Note 1: We restrict this analysis to Sample 2, i.e. households with at least one woman aged 16-45 who is either the household head, spouse, daughter, or daughter-in-law of the household head. Note 2: The figure shows the unconditional trends of the percentage of households with newborns one year after time $t$, for both the treatment and the control group. Series are smoothed to reduce the quarterly volatility. The period "2009 Before" includes births one year after the first or second quarter of 2009, and thus corresponds to fertility decisions prior to the AUH inception

apply an $F$ test in which the null hypothesis ( $\mathrm{Ho}$ ) states that all the coefficients for the interaction terms are jointly equal to zero. We do not find enough evidence to reject $H o$ before the implementation of the program: $F(18,580)=1.14$, Prob $>F=0.3082$; while, in contrast, $H o$ is easily rejected when we include periods after the policy inception: $F(30,964)=1.77$, Prob $>F=0.0071$.

We apply an additional exercise concerning the identification assumption to further assess its validity: a conditional placebo test. To do so, we estimate the same model as in Table 4, column (ii), but we pretend that the program was not implemented in late 2009 but rather at a previous date. Table 5 shows the results for alternative fake dates; in all cases, the coefficient for the interaction variable is clearly non-significant: something happened from the end of 2009 onwards that did not occur at any previous date, as the evidence of these placebo experiments suggests. Of course, the results we find could be due to other events contemporaneous with the AUH, which could have generated a differential impact between groups on fertility outcomes. Although we cannot rule out that possibility, it is important to note that the AUH was a major policy intervention that was not accompanied by other social or labor policy initiatives. Plan Nacer, a large health program with potential impact on fertility, was implemented in 2005. As discussed above, we find a fertility effect only starting in late 2010 , one year after the implementation of the AUH, and not before. 
Table 5 Effect of the AUH on the probability of newborn: Difference in difference estimates. Placebo tests

\begin{tabular}{lllll}
\hline & \multicolumn{2}{l}{ Intervention in } & & \\
\cline { 2 - 5 } & 2008 & 2007 & 2006 & 2005 \\
\hline$T^{*}$ after & -0.00452 & -0.00995 & -0.00163 & 0.000171 \\
& $(0.00845)$ & $(0.00829)$ & $(0.00755)$ & $(0.00721)$ \\
$T$ & 0.00281 & 0.00545 & 0.00269 & 0.00168 \\
& $(0.00506)$ & $(0.00629)$ & $(0.00650)$ & $(0.00620)$ \\
After & 0.00136 & 0.00925 & 0.00169 & -0.00788 \\
Women's and/or household head's characteristics & Yes & Yes & Yes & Yes \\
Other demographic characteristics & Yes & Yes & Yes & Yes \\
Regional and time dummies & Yes & Yes & Yes & Yes \\
Observations & 26,245 & 26,245 & 26,245 & 26,245 \\
Pseudo $R^{2}$ & 0.073 & 0.073 & 0.073 & 0.073 \\
\hline
\end{tabular}

Source: Author's estimations based on EPH microdata (2004-2012)

Note Probit estimations. Marginal effects reported. Estimates based on Sample 2 (households with women between ages 16 to 45 who are either household head, spouse, daughter, or daughter-in-law of the household head) keeping only observations before the AUH implementation. Dependent binary variable: newborn, equals 1 if one year after the household is initially observed, there is any new child younger than 1 year old; $T$ equals 1 for poor and informal households- (bottom four deciles of the household per capita income distribution); in each placebo regression After equals 1 in the period after quarter 4 of the corresponding year. Women's and/or household head's characteristics = gender, age, squared age, educational level and marital status. Other household characteristics = number of members and number of children under 18 years old. Region fixed effects (6 regions) and time fixed effects (quarters). Clustered robust standard errors in parenthesis $* p<0.10 ; * * p<0.05$

\section{Heterogeneity}

We now extend our analysis to explore some possible heterogeneities of this unintended effect. Table 6 reveals that the impact on fertility takes place only for the group of couples that already had children. According to this conditional model, the estimated probability of having a new child during the following year for a couple with children (with observable characteristics similar to the sample mean) increased around 2.2 percentage points (around 35\%) as a consequence of the program. In contrast, the impact of the program on fertility in childless households appears not to be statistically significant.

As previously mentioned, evidence from the demographic literature suggests that fertility intentions are parity-specific (Philipov et al. 2006; Billari et al. 2009). In particular, economic considerations seem to be more relevant for higher order parities than for first births. This is consistent with our findings: the AUH appears to have had a significant impact on fertility for couples with children but not for the group of childless households. In other words, the economic incentives introduced by the AUH seem to have been less relevant, or at least not sufficiently large, to affect the decision of becoming a parent -the extensive margin-, but they seem to 
Table 6 Effect of the AUH on the probability of a newborn: Difference in difference estimates. Households with and without children

\begin{tabular}{llll}
\hline & Total & With children & Without children \\
\hline$T^{*}$ after & $0.0194^{* *}$ & $0.0218^{* *}$ & 0.0103 \\
& $(0.00849)$ & $(0.00959)$ & $(0.0108)$ \\
$T$ & 0.00103 & -0.00236 & 0.00613 \\
& $(0.00540)$ & $(0.00525)$ & $(0.00725)$ \\
After & $0.0202^{*}$ & 0.0193 & -0.0107 \\
& $(0.0115)$ & $(0.0163)$ & $(0.0112)$ \\
Women's and/or household head's characteristics & Yes & Yes & Yes \\
Other demographic characteristics & Yes & Yes & Yes \\
Regional and time dummies & Yes & Yes & Yes \\
Observations & 43,768 & 29,484 & 14,284 \\
Pseudo $R^{2}$ & 0.072 & 0.060 & 0.153
\end{tabular}

Source: Author's estimations based on EPH microdata (2004-2012)

Note Probit estimations. Marginal effects reported. Estimates based on Sample 2 (households with women aged 16-45 who are either household head, spouse, daughter, or daughter-in-law of the household head). Clustered robust standard errors in parenthesis $* p<0.10$; $* * p<0.05$. See notes to Table 3 for more specifications about the regressions

provide a significant incentive for the decision on the number of children-the intensive margin — or on the timing and spacing of births.

Furthermore, it is important to note that the group of households with no children is a highly heterogeneous one, including those who cannot have children, and those who have decided not to procreate yet (or ever). The economic incentives introduced by the inception of a cash program are irrelevant for the first group, but not for the second one. Since we cannot identify these groups in the data, the estimated impact becomes some weighted average of both effects. The results in Table 6 suggest that the program does not affect the incentives of the second group, or at least that the effect is hidden in the overall impact and it is not sufficiently significant to show up.

Given these results, we examine whether there are other heterogeneities in the impact of the program focusing on households with children. Table 7 suggests that fertility outcomes are affected particularly for mothers in the age bracket in which pregnancy is more likely (26-36). Instead, no significant effects are found for younger and older mothers.

We also find that the fertility impact is present for the group of households with 1 to 4 children, but not in couples with 5 or more children (Table 8). This result is not surprising since the household subsidy is capped at 5 children and then does not increase with a sixth child. The result however could also be the consequence of few observations in the sample of large households.

An additional examination reveals that the estimated effect on fertility is relevant for mothers with children younger than 6 years old (Table 8), but it is not 
Table 7 Effect of the AUH on the probability of a newborn: Difference in difference estimates. By mother's age group

\begin{tabular}{llll}
\hline & \multicolumn{2}{l}{ Age groups } & \\
\cline { 2 - 4 } & $16-25$ & $26-36$ & $37-45$ \\
\hline$T^{*}$ after & 0.00124 & $0.0279^{* *}$ & 0.00848 \\
$T$ & $(0.0179)$ & $(0.0132)$ & $(0.00765)$ \\
& -0.0189 & 0.00122 & 0.00105 \\
After & $(0.0131)$ & $(0.00710)$ & $(0.00298)$ \\
& 0.0206 & -0.0180 & -0.00632 \\
Women's and/or household head's characteristics & $(0.0212)$ & $(0.0195)$ & $(0.0103)$ \\
Other demographic characteristics & Yes & Yes & Yes \\
Regional and time dummies & Yes & Yes & Yes \\
Observations & Yes & Yes & Yes \\
Pseudo $R^{2}$ & 5545 & 15,266 & 8673 \\
\hline
\end{tabular}

Source: Author's estimations based on EPH microdata (2004-2012)

Note Probit estimations. Marginal effects reported. Estimates based on households with children from Sample 2 (households with women aged 16-45 who are either household head, spouse, daughter, or daughter-in-law of the household head). Clustered robust standard errors in parenthesis $* p<0.10$; ** $p<0.05$. See notes to Table 3 for more specifications about the regressions

Table 8 Effect of the AUH on the probability of a newborn: Difference in difference estimates. By number and age of children

\begin{tabular}{|c|c|c|c|c|c|}
\hline & \multicolumn{2}{|c|}{ Number of children } & \multicolumn{3}{|c|}{ Age of youngest child } \\
\hline & $1-4$ & 5 or More & $0-6$ & $7-11$ & $12-17$ \\
\hline \multirow[t]{2}{*}{$T *$ After } & $0.0186^{* *}$ & 0.0741 & $0.0247 * *$ & 0.00827 & 0.00336 \\
\hline & $(0.00873)$ & $(0.0520)$ & $(0.0114)$ & $(0.00975)$ & $(0.00657)$ \\
\hline \multirow[t]{2}{*}{$T$} & -0.00188 & 0.00113 & -0.00774 & 0.00237 & 0.00330 \\
\hline & $(0.00570)$ & $(0.0157)$ & $(0.00715)$ & $(0.00426)$ & $(0.00399)$ \\
\hline \multirow[t]{2}{*}{ After } & 0.0191 & -0.00235 & 0.0140 & -0.0338 & -0.0201 \\
\hline & $(0.0159)$ & $(0.0410)$ & $(0.0210)$ & $(0.0265)$ & $(0.0172)$ \\
\hline $\begin{array}{l}\text { Women's and/or household head's } \\
\text { characteristics }\end{array}$ & Yes & Yes & Yes & Yes & Yes \\
\hline Other demographic characteristics & Yes & Yes & Yes & Yes & Yes \\
\hline Regional and time dummies & Yes & Yes & Yes & Yes & Yes \\
\hline Observations & 28,242 & 1188 & 20,277 & 6386 & 2216 \\
\hline Pseudo $R^{2}$ & 0.064 & 0.289 & 0.044 & 0.122 & 0.250 \\
\hline
\end{tabular}

Source: Author's estimations based on EPH microdata (2004-2012)

Note Probit estimations. Marginal effects reported. Estimates based on households with children from Sample 2 (households with women aged 16-45 who are either household head, spouse, daughter, or daughter-in-law of the household head). Clustered robust standard errors in parenthesis $* p<0.10$; $* *$ $p<0.05$. See notes to Table 3 for more specifications about the regressions 
Table 9 Effect of the AUH on the probability of a newborn: Difference in difference estimates. By education level and type of family

\begin{tabular}{|c|c|c|c|c|}
\hline & \multicolumn{2}{|c|}{ Educational level } & \multicolumn{2}{|c|}{ Type of family } \\
\hline & Low & High & $\begin{array}{l}\text { Two- } \\
\text { parent }\end{array}$ & $\begin{array}{l}\text { Single- } \\
\text { parent }\end{array}$ \\
\hline$T *$ after & $\begin{array}{l}0.0299 * \\
(0.0176)\end{array}$ & $\begin{array}{l}0.00583 \\
(0.00987)\end{array}$ & $\begin{array}{l}0.0210 * * \\
(0.00992)\end{array}$ & $\begin{array}{l}0.0107 \\
(0.0103)\end{array}$ \\
\hline$T$ & $\begin{array}{l}0.00757 \\
(0.00920)\end{array}$ & $\begin{array}{l}-0.00869 \\
(0.00577)\end{array}$ & $\begin{array}{l}-0.000769 \\
(0.00515)\end{array}$ & $\begin{array}{l}-0.00785 \\
(0.00641)\end{array}$ \\
\hline After & $\begin{array}{l}0.0331 \\
(0.0271)\end{array}$ & $\begin{array}{l}-0.00154 \\
(0.0104)\end{array}$ & $\begin{array}{l}-0.0105 \\
(0.0101)\end{array}$ & $\begin{array}{l}0.00894 \\
(0.0100)\end{array}$ \\
\hline Women's and/or household head's characteristics & Yes & Yes & Yes & Yes \\
\hline Other demographic characteristics & Yes & Yes & Yes & Yes \\
\hline Regional and time dummies & Yes & Yes & Yes & Yes \\
\hline Observations & 13,004 & 16,407 & 23,112 & 6372 \\
\hline Pseudo $R^{2}$ & 0.060 & 0.090 & 0.055 & 0.160 \\
\hline
\end{tabular}

Source: Author's estimations based on EPH microdata (2004-2012)

Note Probit estimations. Marginal effects reported. Estimates based on households with children from Sample 2 (households with women aged 16-45 who are either household head, spouse, daughter, or daughter-in-law of the household head). The "Low Education" group includes mothers with incomplete high school or lower educational level. Mothers with complete high school or higher level are included in the "High Education" group. Clustered robust standard errors in parenthesis $* p<0.10$; ** $p<0.05$. See notes to Table 3 for more specifications about the regressions

statistically significant for couples with the youngest child older than 6 . The economic incentive introduced by the AUH does not seem to be enough to convince a couple to have another child after a long period since the last birth.

Finally, the probability of having a newborn particularly increases for less educated mothers and it is also significant for two-parent families but not for singleparent households (Table 9).

An important issue is to assess whether the results are due to transient or permanent changes in fertility. Unfortunately, the short time-frame of our analysis does not allow us to identify whether the increase in births after the inception of the new program is a consequence of changes in the equilibrium number of children or if it reflects, instead, a change in the timing of births, without altering the total number of children that couples decide to have.

\section{Concluding Remarks}

The key question of whether fertility is significantly affected by a cash transfer program can only be answered with empirical evidence and in reference to specific concrete cases. We have applied a diff-in-diff strategy in search of evidence for the potential impact on fertility of a large cash transfer program in Argentina aimed at 
poor informal households with children. The results suggest a significant and positive impact on fertility in those households with at least one child, but no significant effect on childless households. Moreover, even among couples in the first group, the impact is small for older and more educated mothers with older children, whose fertility decisions seem to be rather inelastic to the economic incentives introduced by the program. Instead, the impact is larger among those households with younger children and less educated mothers. Unfortunately, we are unable to identify whether the increase in births after the inception of the new program reflects changes in the timing of births or in the equilibrium number of children.

The magnitude of the estimated effect is sizeable: the probability of having an additional child for a couple with observable characteristics similar to the treatment group mean increases almost 2 percentage points after the program's implementation. Insofar as this is an unintended effect of the program, it deserves careful consideration.

It is important to point out that the results presented in this paper have no obvious normative implications. The incentives for larger families that might be associated to the AUH could be considered as a negative or positive outcome, depending on the circumstances and the value judgments of the analyst. For instance, some may not be concerned about the fertility-bias of the program, given that Argentina is a country with low population density. Others, instead, may worry about the increase in the fertility rates of the poor, since larger families may reduce the probability of escaping poverty through various channels. An increase in the number of children raises the denominator in the per capita income variable commonly used to measure income poverty, and also may negatively affect the numerator, as more children may reduce the mother's labor supply, and the ability to take advantage of labor market opportunities, for instance, through migration. ${ }^{22}$ Larger families may also have consequences in the long run, if they imply lower inheritances and lower family spending on education and health per child.

If these arguments are considered relevant, how could the unintended impact of the AUH program on fertility be alleviated? As with most empirical studies, our paper does not provide clear-cut policy implications, although it does suggest some directions to explore. For instance, the program may require parents to attend regular meetings where the government and/or the civil society can provide information on the cost and benefits of larger families, on family planning and on contraceptive methods. Cash payments could easily be made conditional on attendance to those meetings. Also, some fertility patterns may be rewarded in the framework of the program. For instance, benefits could be increased if parents delay the decision to have more children, or the scheme of benefits could be made decreasing in the number of children. This is, however, a sensitive issue: any reform would require more evidence and the assessment of other arguments.

\footnotetext{
22 See Badaracco et al. (2016) for a recent assessment of the direct impact of the changing patterns of fertility in Latin America on income poverty and inequality.
} 


\section{References}

Aaronson, D., Lange, F., \& Mazumder, B. (2014). Fertility transitions along the extensive and intensive margins. American Economic Review, 104(11), 3701-3724.

Acs, G. (1996). The impact of welfare on young mothers' subsequent childbearing decisions. Journal of Human Resources, 31(4), 898-915.

Agis, E., Cañete, C., \& Panigo, D. (2010). El Impacto de la Asignación Universal por Hijo en Argentina. Colección de Textos del Bicentenario, CICCUS/CEIL-PIETTE.

Ajzen, I. (1991). The theory of planned behavior. Organizational Behavior and Human Decision Processes, 50, 179-211.

Alzúa, M. L., Cruces, G., \& Ripani, L. (2013). Welfare programs and labor supply in developing countries. Experimental evidence from Latin America. Journal of Population Economics, 26(4), 1255-1284.

Amarante, V., Manacorda, M., Miguel, E., \& Vigorito, A. (2016). Do cash transfers improve birth outcomes? Evidence from matched vital statistics, and program and social security data. American Economic Journal, 8(2), 1-43.

ANSES. (2012). Boletín Cuatrimestral Asignación Universal por Hijo para Protección Social. III Cuatrimestre 2012. Observatorio de la Seguridad Social, Administración Nacional de la Seguridad Social (ANSES).

Azuara, O., \& Marinescu, I. (2013). Informality and the expansion of social protection programs. Evidence from Mexico. Journal of Health Economics, 32(5), 938-950.

Badaracco, N., Gasparini, L., \& Marchionni, M. (2016). Distributive implications of fertility changes in Latin America. International Journal of Population Research, 2016, Article ID 8717265.

Baudin, T., de la Croix, D., \& Gobbi, P. E. (2015). Fertility and childlessness in the United States. American Economic Review, 105(6), 1852-1882.

Becker, G. S. (1960). An economic analysis of fertility. In Demographic and economic change in developed countries (pp. 209-231), National Bureau of Economic Research. Princeton, NJ: Princeton University Press.

Becker, G. S., \& Lewis, H. G. (1973). On the interaction between the quantity and quality of children. Journal of Political Economy, 81(2), S279-S288.

Bertrand, M., Duflo, E., \& Mullainathan, S. (2004). How much should we trust difference-in-difference estimates? Quarterly Journal of Economics, 119(1), 249-275.

Bertranou, F. (2010). Aportes para la construcción de un piso de protección social en Argentina: El caso de las asignaciones familiares. Buenos Aires: OIT.

Billari, F. C., Philipov, D., \& Testa, M. R. (2009). Attitudes, norms and perceived behavioural control: Explaining fertility intentions in Bulgaria. European Journal of Population, 25, 439-465.

Blau, D., \& Robbins, P. (1989). Fertility, employment and child-care costs. Demography, 26(2), 287-299.

Card, D. (1990). The impact of the Mariel boatlift on the Miami Labor market. Industrial and Labor Relations Review, 43(2), 245-257.

Card, D., \& Krueger, A. (1994). Minimum wages and employment: A case of study of the fast-food industry in New Jersey and Pennsylvania. American Economic Review, 84, 772-793.

Cigno, A., \& Pinal, G. (2004). Endogenous child mortality, price of child-specific goods and fertility decisions: Evidence from Argentina. In D. Heymann, F. Navajas, \& E. Bour (Eds.), Latin American economic crises. London: Palgrave Macmillan.

Cohen, A., Dehejia, R., \& Romanov, D. (2013). Financial incentives and fertility. Review of Economics and Statistics, 95(1), 1-20.

D’Elia, V., Calabria, A., Calero, A., Gaiada, J., \& Rottenschweiler, S. (2010). Asignación Universal por Hijo para Protección Social: Una política de Protección para los más vulnerables. Revista del Centro Interamericano de Estudios de la Seguridad Social (CIESS) No 260.

D'Elia, V., \& Navarro, A. (2011). The impact of the universal child allowance on Argentinás children schooling gap. Proceedings of the AAEP.

Deaton, A. (2003). How to monitor poverty for the millennium development goals. Journal of Human Development, 4(3), 353-378.

Duflo, E., Glennerster, R., \& Kremer, M. (2006). Using randomization in development economics research: A toolkit. NBER Technical Working Paper 333. 
Dyer, W., \& Fairlie, R. (2003). Do family caps reduce out-of-wedlock births? Evidence from Arkansas, Georgia, Indiana, New Jersey, and Virginia. Yale University, Economic Growth Center Discussion Paper No. 877.

Ebenstein, A. (2010). The 'Missing Girls' of China and the unintended consequences of the one child policy. Journal of Human Resources, 45(1), 87-115.

Edo, M., Marchionni, M., \& Garganta (2015). Conditional cash transfer programs and enforcement of compulsory education laws. The case of Asignación Universal por Hijo in Argentina. CEDLAS Working Paper N. 190.

Fairlie, Robert W., \& London, Rebecca A. (1997). The effect of incremental benefit levels on births to AFDC recipients. Journal of Policy Analysis and Management, 16(4), 575-597.

Fiszbein, A., Schady, N., Ferreira, F., Grosh, M., Keleher, N., Olinto, P., \& Skoufias, E. (2009). Conditional cash transfers: Reducing present and future poverty. Washington, DC: World Bank Publications.

Garganta, S., \& Gasparini, L. (2015). The impact of a social program on labor informality: The case of AUH in Argentina. Journal of Development Economics, 115, 99-110.

Gasparini, L., Cicowiez, M., \& Sosa Escudero, W. (2013). Pobreza y Desigualdad en América Latina: Conceptos, herramientas y aplicaciones. Buenos Aires: Editorial Temas.

Gasparini, L., \& Cruces, G. (2010). Las asignaciones universales por hijo. impacto, discusión y alternativas. Revista Económica. LVI, 1, 105-146.

Gonzalez-Rozada, M., \& Pinto, F. L. (2011). The effects of a CCT on the labor market: The human development bonus in Ecuador. Universidad Torcuato Di Tella, Department of Economics Working Papers, 2011.

Grogger, J., Karoly, L., \& Klerman, A. (2002). Consequences of welfare reform: A research synthesis. Los Angeles, CA: The RAND Corporation.

Groisman, F., Bossert, F., \& Sconfienza, M. E. (2014). Políticas de protección social y participación económica de la población en Argentina (2003-2010). Desarrollo Económico, 51, 202-203.

Hoynes, H. M. (1997). Work, welfare, and family structure. In A. J. Auerbach (Ed.), Fiscal policy: Lessons from economic research. Cambridge, MA: MIT Press.

Joyce, T., Kaestner, R., \& Korenman, S. (2003). Welfare Reform and non-marital fertility in the 1990s: Evidence from birth records. Advances in Economic Analysis and Policy, 3(1), Article 6.

Kearny, M. (2004). Is there an effect of incremental welfare benefits on fertility behavior? A look at the family cap. Journal of Human Resources, 39, 295-325.

Laroque, G., \& Salanié, B. (2013). Identifying the response of fertility to financial incentives. Journal of Applied Econometrics, 29, 314-332.

Lustig, N., Jaramillo, M., Pessino, C., \& Scott, J. (2012). Commitment to equity: An assessment of fiscal policies in Argentina, Mexico and Peru. New York: Mimeo.

Milligan, K. (2005). Subsidizing the stork. New evidence on tax incentives and fertility. Review of Economics and Statistics, 87(3), 539-555.

Moffitt, R. (1998). The effect of welfare on marriage and fertility: What do we know and what do we need to know? In R. Moffitt (Ed.), The family and reproductive behavior: Research perspectives. Washington: National Academy Press.

Moreno, J. M. (2006). La protección social en Argentina. Banco Mundial, manuscript.

Nandi, A., \& Laxminarayan, R. (2016). The unintended effects of cash transfers on fertility: Evidence from the Safe Motherhood Scheme in India. Journal of Population Economics, 29(2), 457-491.

Oster, E. (2005). Hepatitis B and the case of the missing women. Journal of Political Economy, 113(6), 1163-1216.

Pacharoni, V., \& Ronconi, L. (2014). El impacto de la Asignación Universal por Hijo sobre la Tasa de Fecundidad. Proceedings of the AAEP.

Palermo, T., Handa, S., Peterman, A., Prencipe, L., \& Seidenfeld, D. (2015). Unconditional government social cash transfer in Africa does not increase fertility. Innocenti Working Paper, 2015-09 (UNICEF Office of Research).

Paz, J., \& Golovanevsky, L. (2014), Programa Asignación Universal por Hijo para la Protección Social. Un ejercicio de evaluación de sus efectos sobre los hogares. III Jornadas Nacionales sobre Estudios Regionales y Mercados de Trabajo, Jujuy, Argentina.

Philipov, D., Spéder, Z., \& Billari, F. C. (2006). The impact of anomie and social capital on fertility intentions in Bulgaria (2002) and Hungary (2001). Population Studies, 60, 289-308.

Puhani, P. (2012). The treatment effect, the cross difference and the interaction term in nonlinear difference-in-difference models. Economics Letters, 115(1), 85-87. 
Rofman, R., \& Oliveri, M. (2011). Las Políticas de Protección social y su impacto en la distribución del Ingreso en Argentina. Working Paper Series on Social Policy No 6, World Bank.

Rosenzweig, Mark R. (1999). Welfare, marital prospects, and nonmarital childbearing. Journal of Political Economy, 107(6), S3-S32.

Rosenzweig, M. R., \& Schultz, T. P. (1985). The demand for and supply of births: Fertility and its life cycle consequences. American Economic Review, 75(5), 992-1015.

Schultz, T. P. (1997). Demand for children in low income countries. In M.R. Rosenzweig \& O. Stark (Eds.), Handbook of population and family economics. New York: Elsevier.

Signorini, B. A., \& Queiroz, B. (2011). The impact of the Bolsa Família program in the beneficiary fertility. Texto para Discussão 439, Cedeplar-Universidade Federal de Minas Gerais (UFMG).

Stampini, M., \& Tornarolli, L. (2013). The growth of conditional cash transfers in Latin America and the Caribbean: Did they go too far? Proceedings of the AAEP, Rosario.

Stecklov, G., Winters, P., Todd, J., \& Regalia, F. (2007). Unintended effects of poverty programmes on childbearing in less developed countries: Experimental evidence from Latin America. Population Studies, 61(2), 125-140.

Todd, J., Winters, P., \& Stecklov, G. (2012). Evaluating the impact of conditional cash transfer programs on fertility: The case of Red de Protección Social in Nicaragua. Journal of Population Economics, 25(1), 267-290.

Whittington, L., Alm, J., \& Peters, H. (1990). Fertility and the personal exemption-implicit pronatalist policy in the United States. American Economic Review, 80(3), 545-556. 